\title{
Impacts of Nitrogen Starvation on Expression Profiles of Involving Genes in Triacylglycerol Biosynthesis in Chlamydomonas reinhardtii: Towards Microalgal Systems Biotechnology
}

\author{
Mohammad Hossein Morowvat ${ }^{1 *}$, Younes Ghasemi² \\ 'Pharmaceutical Sciences Research Center, Shiraz University of Medical Sciences, P.O. Box 71345-1583, Shiraz, IRAN. \\ 2Department of Pharmaceutical Biotechnology, School of Pharmacy, Shiraz University of Medical Sciences, P.O. Box 71468-64685, Shiraz, IRAN.
}

\begin{abstract}
Objective: Chlamydomonas reinhardtii, the most commonly studied model organism in microalgal kingdom, is known to be a rich lipid producer. Methods: Here, a naturally isolated C. reinhardtii strain was cultivated phototrophically at Erlenmeyer scale in BG11 culture medium. After reaching to stationary growth phase, a nitrogen limited regime with different nitrogen concentrations was applied. Results: Quantitative real time PCR analysis of DGTT1 and DGTT2 genes involved in triacylglycerol accumulation confirmed an increased level of expression for DGTT1 (21.05-fold increase) in nitrogen starvation compared with the nitrogen rich conditions. Besides, DGTT2 transcript levels showed a slight decrease in nitrogen deprivation condition (0.61-fold). Conclusion: The results opened a new way to direct microalgal systems biotechnology towards maximization of triacylglycerol
\end{abstract}

production for green energy production.

Key words: Chlamydomonas reinhardtii, Expression profile, Nitrogen starvation, Systems biotechnology, Triacylglycerol.

Key message: The expression profiles of DGTT1 and DGGT2 genes change during nitrogen starvation in $C$. reinhardti.

Correspondence :

Mohammad Hossein Morowvat, Pharmaceutical Sciences Research Center, Shiraz University of Medical Sciences, P.O. Box 71345-1583, Shiraz, IRAN.

Phone: +98-71 32426729

Email: mhmorowvat@sums.ac.ir

DOI: 10.5530/jyp.2017.9.97

\section{INTRODUCTION}

In recent years, with rising prices for fossil fuels, apprehensions about the completion of a variety of energy resources and global concerns about environmental pollution caused by fossil fuels utilization, the global needs for clean and renewable sources of energy, is demanded more than ever. ${ }^{1}$ Among the various alternative energy sources, exploitation of eukaryotic microalgae, as a renewable and affordable fuel source, seems very feasible, and nowadays many studies have been conducted by researchers all around the world. ${ }^{2}$

Microalgae are fast growing organisms with high contents of lipids which make them reproducible and reliable sources for biodiesel production. Nevertheless, the biggest problem in the way of their use, is their poor lipid productivity and yield and the final costs of biodiesel production. Therefore, approaches to increase the lipid productivity and reducing the final costs seems critical. ${ }^{3}$

Changes in environmental conditions such as temperature, light intensity and number of minerals in the medium, such as adding iron or urea nitrogen or phosphorus to culture medium or lowering its amounts makes up the bulk of microalgae lipid content in the form of triacylglycerol (TAG) stores. ${ }^{4}$ TAG is obtained from a combination of three fatty acids esterified with glycerol. All eukaryotic organisms can synthesize TAGs, and the main constitute of the lipid contents in vegetable oils and animal fats is considered to be TAG. ${ }^{5}$ Nevertheless, the details of the molecular mechanisms involved in TAG accumulation phenomenon is still in its infancy. Although, the eukaryotic microalga Chlamydomonas reinhardtii has not been regarded as a biodiesel producer in industrial scale, it has been considered as the preferred molecular model organisms over other species of microalgae. ${ }^{6}$ Besides, due to its available complete genome sequence ${ }^{7}$, it has been regarded as an attractive model to study many biological phenomena such as starch or lipid metabolism, energy carrier synthesis, photosynthesis, or cellular responses to nutrient starvation. C. reinhardtii is capable of phototrophic or heterotrophic metabolism and shows a high responsive capability against the environmental stressors in the form of metabolic changes. However, the details of TAG metabolism in C. reinhardtii, has been merely studied. On the other hand, the TAG production pathway is a vital part to optimize a robust process for microalgal biodiesel production.

Two distinct acyltransferases, diacylglycerol transferases (DGAT) and phospholipid: diacylglycerol acyltransferase (PDAT) are involved in TAG biosynthesis in different organisms. ${ }^{8}$ After complete genome sequencing of $C$. reinhardtii microalga ${ }^{7}$, it was discovered that there is only one type 1 DGAT (DGAT1) in its genome, whilst five different encoding gene are responsible for type 2 DGAT (DGTT1 to DGTT5). ${ }^{9}$

Some studies have been dealt with the mechanisms involved in TAG production during nutrient depletion in C. reinhardtii. ${ }^{10,11}$ Nevertheless, there is still a controversy in the results of previous studies and the exact role of each acyltransferase enzyme in TAG accumulation phenomena is still unveiled.

Here we investigated the expression profile of DGTT1 and DGTT2 genes during nitrogen limitation in naturally isolated C. reinhardtii strain. Beside its growth kinetics, biomass and lipid production and productivity and TAG content of lipids in presence of different nitrogen levels were also examined. The molecular detailed of TAG accumulation phenomena might be useful to increase the biosynthesis of TAG, improve the lipid productivity and reduce the operating costs of microalgal biodiesel production. Besides, the results of this study could be used for $C$. reinhardtii systems biotechnology towards overproduction of TAG and other valuable bioactive compounds. 


\section{MATERIALS AND METHODS}

\section{Strain and culture medium}

The C. reinhardtii (Chlorophyta, Chlorophyceae) strain obtained from the Microalgal Culture Collection of Shiraz University of Medical Sciences (MCCS), Shiraz, Iran was cultivated in sterile BG11 culture medium composed of (per liter): $\mathrm{NaNO}_{3}(1.5 \mathrm{~g}) ; \mathrm{K}_{2} \mathrm{HPO}_{4}(0.04 \mathrm{~g}) ; \mathrm{MgSO}_{4} \cdot 7 \mathrm{H}_{2} \mathrm{O}$ $(0.075 \mathrm{~g}) ; \mathrm{CaCl}_{2} .2 \mathrm{H}_{2} \mathrm{O}(0.036 \mathrm{~g})$; citric acid $(0.006 \mathrm{~g})$; ferric ammonium citrate $(0.006 \mathrm{~g})$; Na $\mathrm{Na}_{2}$ EDA $(0.001 \mathrm{~g}) ; \mathrm{Na}_{2} \mathrm{CO}_{3}(0.02 \mathrm{~g})$ and the trace element solution $(10 \mathrm{~mL})\left(\mathrm{H}_{3} \mathrm{BO}_{3}\left(2.86 \mathrm{mg} \mathrm{L}^{-1}\right) ; \mathrm{MnCl}_{2} \cdot 4 \mathrm{H}_{2} \mathrm{O}(1.81 \mathrm{~g}\right.$ $\left.\mathrm{L}^{-1}\right) ; \mathrm{ZnSO}_{4} .7 \mathrm{H}_{2} \mathrm{O}\left(0.222 \mathrm{~g} \mathrm{~L}^{-1}\right) ; \mathrm{Na}_{2} \mathrm{MoO}_{4} \cdot 2 \mathrm{H}_{2} \mathrm{O}\left(0.39 \mathrm{~g} \mathrm{~L}^{-1}\right) ; \mathrm{CuSO}_{4} \cdot 7 \mathrm{H}_{2} \mathrm{O}$ $\left.\left(0.079 \mathrm{~g} \mathrm{~L}^{-1}\right) ; \mathrm{Co}\left(\mathrm{NO}_{3}\right)_{2} \cdot 6 \mathrm{H}_{2} \mathrm{O}\left(0.0494 \mathrm{~g} \mathrm{~L}^{-1}\right)\right){ }^{12}$ After examining the uniformity and possible contamination in the obtained microalgal sample, the growth study of $C$. reinhardtii was observed for 21 days. The experiment performed in $500 \mathrm{~mL}$ Erlenmeyer flasks containing $200 \mathrm{~mL}$ of culture media. The flasks were incubated at $25^{\circ} \mathrm{C}$ in an orbital incubator shaker (PECO, Iran). The cultivation conditions for $96 \mathrm{~h}$ were set at the agitation rate of $130 \mathrm{rpm}$ and the light intensity of $60 \mathrm{~mol} \mathrm{~m}^{-2} \mathrm{~s}^{-1}$ to obtain the final cell concentration of about $30 \times 10^{4}$ cell $\mathrm{mL}^{-1}$. After 10 days of cultivation, this primary seed culture was employed as a standard inoculum for further studies in shake flask experiment.

\section{Cultivation conditions}

Two modes of cultivation including normal and nitrogen starved conditions. In normal cultivation mode, the pre-cultured C. reinhardtii cells were transferred to three distinct $500 \mathrm{~mL}$ Erlenmeyers containing 200 $\mathrm{mL}$ of fresh BG11 medium. The cultivation procedure was continued for another 11 days under previously described conditions. In nitrogen starvation mode, $C$. reinhardtii cells from previous section was initially centrifuged at $3000 \times g, 20^{\circ} \mathrm{C}$ for $5 \mathrm{~min}$. The separated microalgal cells were washed using an isotonic normal saline solution $\left(0.09 \mathrm{~g} \mathrm{NaCl} \mathrm{L}^{-1}\right)$ twice to remove the possible cell debris. The obtained pellet was then resuspended in $200 \mathrm{~mL}$ of nitrogen starved medium (containing the BG11 medium without $\mathrm{NaNO}_{3}$ ). The starvation experiment was also exploited in triplicate and the mean values for the observed trends were reported.

\section{RNA extraction procedure}

The microalgal cells were centrifuged at $3500 \mathrm{rpm}, 4^{\circ} \mathrm{C}$ for $5 \mathrm{~min}$ and then the total RNA content was isolated using a commercially available RNA extraction kit (catalog number: RN7713C) (RNX ${ }^{\mathrm{TM}}$-PLUS buffer provided by SinaClon company, Tehran, Iran) according to the provided protocol by manufacturer. Briefly, $1 \mathrm{~mL}$ of the ice cold RNA ${ }^{\mathrm{TM}}$-PLUS solution and $1 \mathrm{~mL}$ of the microalgal supernatant were transferred to a poly propylene tube. It was vortexed for $10 \mathrm{sec}$ and then incubated for $5 \mathrm{~min}$ at room temperature. $200 \mu \mathrm{L}$ of chloroform was as added to the mixture and mixed for $15 \mathrm{sec}$. It was then incubated on ice for $5 \mathrm{~min}$ at $0{ }^{\circ} \mathrm{C}$. Next it was centrifuged at $12000 \mathrm{rpm}$ at $4^{\circ} \mathrm{C}$ for $15 \mathrm{~min}$. The obtained aqueous phase was transferred to a new $1.5 \mathrm{~mL}$ RNase-free tube and an equal volume of isopropanol was added to it. It was gently mixed and incubated on ice for $15 \mathrm{~min}$ at $0{ }^{\circ} \mathrm{C}$. The mixture was centrifuged at $12000 \mathrm{rpm}$ at $4{ }^{\circ} \mathrm{C}$ for $15 \mathrm{~min}$. The obtained supernatant was discarded and ethanol $(75 \%, 1 \mathrm{~mL})$ was added to the tube. It was vortexed for 10 sec to dislodge the pellet. It was then centrifuged at $7500 \mathrm{rpm}$ and $4{ }^{\circ} \mathrm{C}$ for $8 \mathrm{~min}$. The supernatant was removed and the pellet was remained (5 min) till drying at room temperature. The resulted pellet was dissolved in DEPC treated water $(50 \mu \mathrm{L})$. To improve the dissolving process, the test tube was placed in $55^{\circ} \mathrm{C}$ water bath for $10 \mathrm{~min}$. The purified total RNA was quantified using spectrophotometrically (Pico Drop P200, Alfa Biotech, Glasgow, UK). The prepared RNA was then treated with DNase I (RNase-free) kit (E. C. 3.1.21.1, catalog number: AM2222) (Thermo Fischer Scientific, Massachusetts, USA) to reduce the possible genomic DNA contents. To synthesize the first strand cDNA sequence, RevertAid Reverse Transcriptase (200 U $\mathrm{LL}^{-1}$ ) (catalog number: EP0441) (Thermo Fischer Scientific, Massachusetts, USA) was employed with oligo dT primers in the final volume of $20 \mu \mathrm{L}$.

\section{Primer design}

AlleleID software version 7.83 for windows, PREMIER Biosoft, Palo Alto, CA, USA was used for designing the target primers for $18 \mathrm{~S} r \mathrm{RA}$ gene (FJ864686.1) from another C. reinhardtii strain $^{13}$ as an internal control gene, DGTT1 (KC788199) and DGTT2 (KC788200) genes. ${ }^{9}$ The designed forward and reverse primers for three mentioned genes with their amplification length and other properties are presented in Table 1.

\section{Real time PCR protocol}

Real-time PCR experiment was performed using MiniOpticon thermal cycler system (Bio-Rad Laboratories Inc., Hercules, CA, US) with Opticon Monitor $^{\mathrm{rst}}$ analysis software control. The reaction was exploited in a total volume of $20 \mu \mathrm{L}$. In each tube, $1 \mu \mathrm{L}$ of cDNA, $10 \mu \mathrm{L}$ SYBR $^{\circ}$ Premix Ex $\mathrm{Taq}^{\mathrm{m}}$ II (TaKaRa, Japan) and 4 pmol of each designed primer was used. The employed real-time PCR cycle were optimized at $94^{\circ} \mathrm{C}$ for $2 \mathrm{~min}$ as initial denaturation step, followed by 40 cycles of amplification at $94^{\circ} \mathrm{C}$ for $10 \mathrm{sec}$, differing respect to the annealing temperature $(\mathrm{Ta})$ for each employed primer for 15 and 30 secs of extension $\left(72^{\circ} \mathrm{C}\right)$. Besides, two different negative controls including a reaction without reverse transcriptase enzyme and another without cDNA template were also examined. At the end of PCR reaction, the amplified products were used to analyze the dissociation curves. Moreover, it was confirmed that there is only a PCR product for each PCR reaction. Triplicate experiments were performed for each sample. To determine the relative fold of quantification, adopted DDCT method ${ }^{14}$ was employed. The observed differences at a level of 5\% was regarded as significant. GraphPad prism version 6.00 (GraphPad Software, La Jolla California, USA) was employed for the statistical analysis.

\begin{tabular}{|c|c|c|c|c|}
\hline Primer & $\begin{array}{c}\text { Primer } \\
\text { Length (bp) }\end{array}$ & $\operatorname{Tm}\left({ }^{\circ} \mathrm{C}\right)$ & $\begin{array}{l}\text { Amplicon } \\
\text { length }\end{array}$ & Sequence \\
\hline DGTT1 F & 23 & 56.52 & 996 & ACATAATAGAGGTACAGCAGGAA \\
\hline DGTT1 R & 20 & 64.07 & 996 & CGCTGGCCATCGTGCAATGA \\
\hline DGTT2 F & 20 & 56.55 & 975 & ATGGCGATTGATAAAGCACC \\
\hline DGTT2 R & 20 & 62.23 & 975 & TCAGCTGATGACCAGCGGTC \\
\hline 18S rRNA F & 25 & 57.31 & 148 & GTCAGAGGTGAAATTCTTGGATTTA \\
\hline 18S rRNA R & 21 & 62.44 & 148 & AGGGCAGGGACGTAATCAACG \\
\hline
\end{tabular}




\section{Compositional analysis}

To determine the growth profile of the studied microalga, dry cell weight method was employed. $10 \mathrm{~mL}$ of each cultures medium was aseptically transferred to a test tube and centrifuged for $5 \mathrm{~min}$ at $10000 \mathrm{~g}$ and $4{ }^{\circ} \mathrm{C}$. The obtained C. reinhardtii pellets were washed twice with an isotonic normal saline solution $\left(0.09 \mathrm{~g} \mathrm{NaCl} \mathrm{L}^{-1}\right)$. To remove the possible impurities, it was centrifuged again. The final microalgal pellets were dried at $95{ }^{\circ} \mathrm{C}$ overnight. The total lipid contents of $C$. reinhardtii was extracted using a previously adopted protocol with some modifications. ${ }^{15}$ Briefly, $1 \mathrm{~g}$ of biomass was boiled for $2 \mathrm{~min}$ in isopropanol followed by homogenization in chloroform-methanol (1:2) mixture with butylated hydroxytoluene (BHT) $(0.05 \% \mathrm{w} / \mathrm{v})$ as antioxidant. Then a mixture of water and chloroform ( 0.8 and $5 \mathrm{~mL}$ respectively), enriched by an aqueous solution of potassium chloride $(0.88 \mathrm{w} / \mathrm{v})$ was added. After vigorous shaking, the obtained solvent phase was collected and then dried under nitrogen gas. To investigate the total lipid content of $C$. reinhardtii, the gravimetric method was utilized.

After cell lysis using the rapid heating and cooling method, TAGs were measured using cooled-blank method with an assay kindly provided by Taylor L. Weiss, Department of Biology, Washington University, Saint Louis, US (personal communication)., It includes three $1.5 \mathrm{~mL}$ tubes each containing final volumes of $400 \mu \mathrm{L}$. Distilled water $(400 \mu \mathrm{L})$ was used as blank. The glycerol standard solution was $2.5 \mathrm{mg} \mathrm{mL}^{-1}$ equivalent triolein concentration (catalog number: G7793, Sigma-Aldrich, Saint Louis, MO, US). $380 \mu \mathrm{L}$ of above mentioned glycerol standard solution was mixed with $20 \mu \mathrm{L}$ distilled water before application. The sample cuvette contained $20 \mu \mathrm{L}$ of the extracted cell lysate and $380 \mu \mathrm{L}$ of a commercially available serum triglyceride determination kit (catalog number: TR0100, Sigma-Aldrich, Saint Louis, MO, US). The described tubes were gently mixed and then centrifuged at $12000 \mathrm{rpm}, 4^{\circ} \mathrm{C}$ for $2 \mathrm{~min}$. after removing the cell debris, $350 \mu \mathrm{L}$ of each solution was used for TAG determination assay using spectrophotometrically at $520 \mathrm{~nm}$. The experiment was performed in triplicate and the mean values were used to calculate the triolein concentration using the below equation (Eq. 1):

Triolein conc. $=\frac{\left(\mathrm{Abs}_{\text {sample reaction }}-\mathrm{Abs}_{\text {sample blank }}\right)}{\left(\mathrm{Abs}_{\text {standard reaction }}-\mathrm{Abs}_{\text {stan dard blank }}\right)} \times\left(\frac{\text { Standard conc. }}{\text { Dilution factor }}\right)($ Eq. 1)

in which the dilution factor was regarded as 5 .

\section{RESULTS AND DISCUSSION}

\section{Cell growth, biomass and growth kinetics}

The microalgal growing pattern was observed in normal and nitrogen limitation conditions during 28 days of cultivation composed of 10 days of normal cultivation and another 12 days of cultivation in a fresh culture medium with the same composition $\left(\mathrm{N}_{1}\right)$ or 12 days of nitrogen limitation $\left(\mathrm{N}_{0}, \mathrm{~N}_{2}\right.$ and $\left.\mathrm{N}_{3}\right)$ mode. The employed method for growth measurement was dry cell weight method in which the sampling was performed every two days Figure 1. C. reinhardtii cells displayed a typical sigmoidal growth pattern in both studied cultures. During first six days of cultivation, the microalgal cells remained in their lag phase, and entered to the logarithmic phase of growth from the $6^{\text {th }}$ day to the $25^{\text {th }}$ day of cultivation followed by the stationary and death phases from $25^{\text {th }}$ to the $28^{\text {th }}$ day. The microalgal cells grew faster in normal cultivation mode than in the nitrogen limited conditions. The maximum obtained dry cell weight $\left(X_{\max }\right)$ and the biomass productivity $\left(P_{\max }\right)$ were found to be $1.548 \mathrm{~g} \mathrm{~L}^{-1}$ and $0.085 \mathrm{~g} \mathrm{~L}^{-1} \mathrm{~d}^{-1}\left(\mathrm{~N}_{0}\right) ; 5.115 \mathrm{~g} \mathrm{~L}^{-1}$ and $0.232 \mathrm{~g} \mathrm{~L}^{-1} \mathrm{~d}^{-1}\left(\mathrm{~N}_{1}\right) ; 3.127 \mathrm{~g} \mathrm{~L}^{-1}$ and $0.207 \mathrm{~g} \mathrm{~L}^{-1} \mathrm{~d}^{-1}\left(\mathrm{~N}_{2}\right)$ and $1.861 \mathrm{~g} \mathrm{~L}^{-1}$ and $0.113 \mathrm{~g} \mathrm{~L}^{-1} \mathrm{~d}^{-1}\left(\mathrm{~N}_{3}\right)$ Table 2. On the other word, nitrogen limitation caused a noticeable reduction in biomass production up $30.26 \%\left(\mathrm{~N}_{0}\right)$; $61.13 \%\left(\mathrm{~N}_{2}\right)$ and $36.38 \%\left(\mathrm{~N}_{3}\right)$ compared with the normal cultivation mode $\left(\mathrm{N}_{1}\right)$. The observed phenomenon in

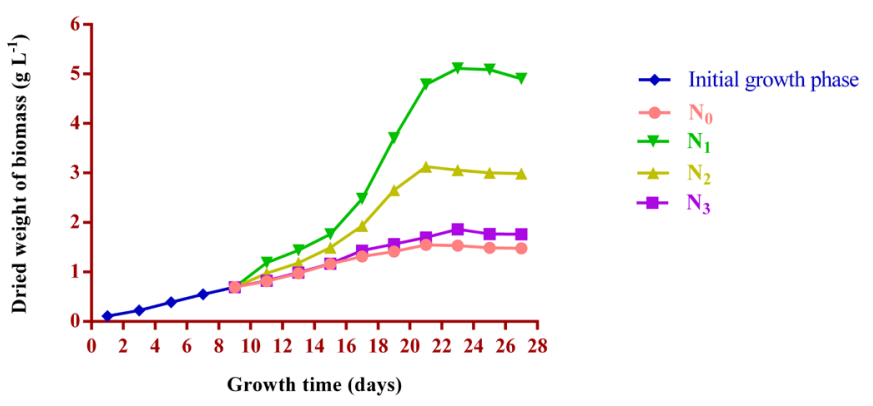

Figure 1: Growth rate of $C$. reinhardtii under different concentrations of nitrogen in shake flask scale during 28 days of study using dry cell weight method.

Table 2: The growth parameters, cell number, maximum biomass and lipid productivities in the studied $C$. reinhardtii strain under different nitrogen concentrations during 28 days of study

\begin{tabular}{ccccc}
\hline Cultivation mode & \multicolumn{2}{c}{ Growth parameters } & \multicolumn{2}{c}{ Productivity } \\
\hline $\mathbf{X}_{\max }$ & $\boldsymbol{\mu}_{\max }$ & $\mathbf{P}_{\max }$ & $\mathbf{L}_{\max }$ \\
$\mathbf{N}_{\mathbf{0}}\left(\mathbf{0} \mathbf{g ~ L}^{-1}\right)$ & 1.548 & 0.017 & 0.085 & 0.021 \\
$\mathbf{N}_{\mathbf{1}}\left(\mathbf{1} . \mathbf{5} \mathbf{g ~ L}^{-1}\right)$ & 5.115 & 0.092 & 0.232 & 0.110 \\
$\mathbf{N}_{\mathbf{2}}\left(\mathbf{1 . 0} \mathbf{g ~ L}^{-1}\right)$ & 3.127 & 0.066 & 0.207 & 0.075 \\
$\mathbf{N}_{\mathbf{3}}\left(\mathbf{0 . 5} \mathbf{g ~ L}^{-1}\right)$ & 1.861 & 0.035 & 0.113 & 0.093 \\
\hline
\end{tabular}

${ }^{*} X_{\max }=$ maximum biomass concentration $\left(\mathrm{g} \mathrm{L}^{-1}\right) ; \mu_{\max }=$ maximum specific growth rate $\left(\mathrm{d}^{-1}\right) ; P_{\max }=$ maximum biomass productivity $\left(\mathrm{g} \mathrm{L}^{-1} \mathrm{~d}^{-1}\right) ; \mathrm{L}_{\max }=$ maximum lipid productivity $\left(\mathrm{g} \mathrm{L}^{-1} \mathrm{~d}^{-1}\right) ; \mathrm{N}_{0}=$ cultivation at $0 \mathrm{~g} \mathrm{~L}^{-1}$ nitrogen; $\mathrm{N}_{1}=$ cultivation at 1.5 $\mathrm{g} \mathrm{L}^{-1}$ nitrogen; $\mathrm{N}_{2}=$ cultivation at $1.0 \mathrm{~g} \mathrm{~L}^{-1}$ nitrogen; $\mathrm{N}_{3}=$ cultivation at $0.5 \mathrm{~g} \mathrm{~L}^{-1}$ nitrogen.

biomass production trends might be attributed to the unfavored physiologic circumstances due to lowered levels of nitrogen in the culture medium. The same results have been reported by other researchers studying the effects of nitrogen depletion on biomass production and growth rates in C. reinhardtii. ${ }^{16,17}$

\section{Lipid production and productivity}

Moreover, the influences of different nitrogen levels on lipid production and productivity was also examined Figure $2 \mathrm{a}-\mathrm{d}$. As presented in Figure 2a, the accumulated lipids in the normal cultivation conditions $\left(\mathrm{N}_{1}\right)$ was reached to $1.337 \mathrm{~g} \mathrm{~L}^{1}$. The maximum lipid productivity in this cultivation was reached up to $0.110 \mathrm{~g} \mathrm{~L}^{-1} \mathrm{~d}^{-1}$. On the other word, the total lipid content in $\mathrm{N}_{1}$ medium was $26.14 \%$ in the total produced biomass. At the end of cultivation process, the final obtained lipid production from three different nitrogen depleted media reached to $0.849 \mathrm{~g} \mathrm{~L}^{-1}\left(\mathrm{~N}_{2}\right)$ Figure $2 \mathrm{~b}, 0.635 \mathrm{~g} \mathrm{~L}^{-1}$ $\left(\mathrm{N}_{3}\right)$ Figure $2 \mathrm{c}$ and $0.783 \mathrm{~g} \mathrm{~L}^{-1}\left(\mathrm{~N}_{0}\right)$ Figure $2 \mathrm{~d}$. The reported values were equal to $28.05 \%\left(\mathrm{~N}_{2}\right), 34.12 \%\left(\mathrm{~N}_{3}\right)$ and $42.07 \%\left(\mathrm{~N}_{0}\right)$. In this context, the observed lipid productivity values were noticed to be $0.021 \mathrm{~g} \mathrm{~L}^{-1} \mathrm{~d}^{-1}, 0.075$ $\mathrm{g} \mathrm{L}^{-1} \mathrm{~d}^{-1}$, and $0.093 \mathrm{~g} \mathrm{~L}^{-1} \mathrm{~d}^{-1}$, at $\mathrm{N}_{0}\left(0 \mathrm{~g} \mathrm{~L}^{-1}\right), \mathrm{N}_{2}\left(1.0 \mathrm{~g} \mathrm{~L}^{-1}\right)$ and $\mathrm{N}_{3}\left(0.5 \mathrm{~g} \mathrm{~L}^{-1}\right)$, respectively. On the other words, nitrogen depletion, caused a noticeable decrease in the lipid productivity trends.

The observed results from growth kinetics and productivity studies in C. reinhardtii strain were in agreement with the provide results by other researchers. ${ }^{18,19}$ It could be concluded that higher amounts of lipid accumulation were occurred in nitrogen limited conditions. The obtained data implied the standing contribution of nitrogen concentrations in biomass biosynthesis pathways. However, concerning the lipid production and productivity trends, it was indicated that nitrogen depletion 

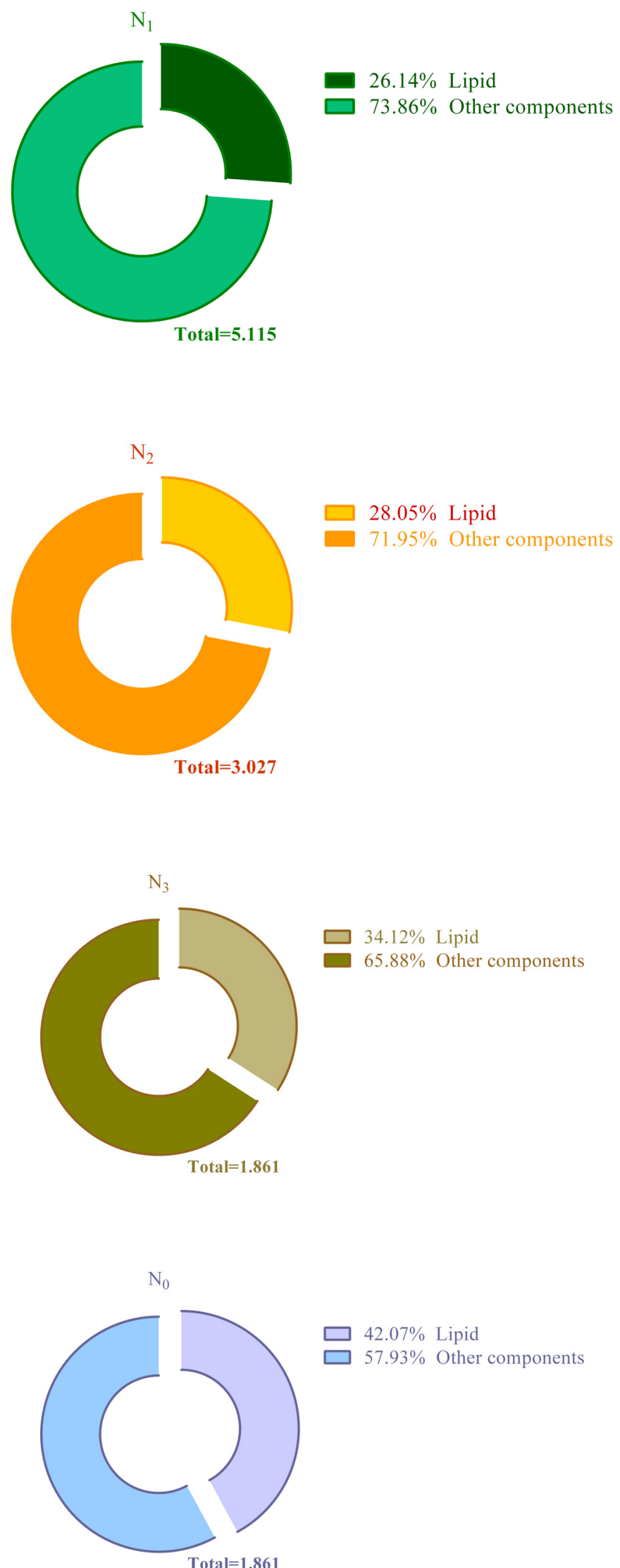

Figure 2: The total lipid content of $C$. reinhardtii under different concentrations of nitrogen $(a-d)(\% \mathrm{w} / \mathrm{w})$ in the final obtained biomass.
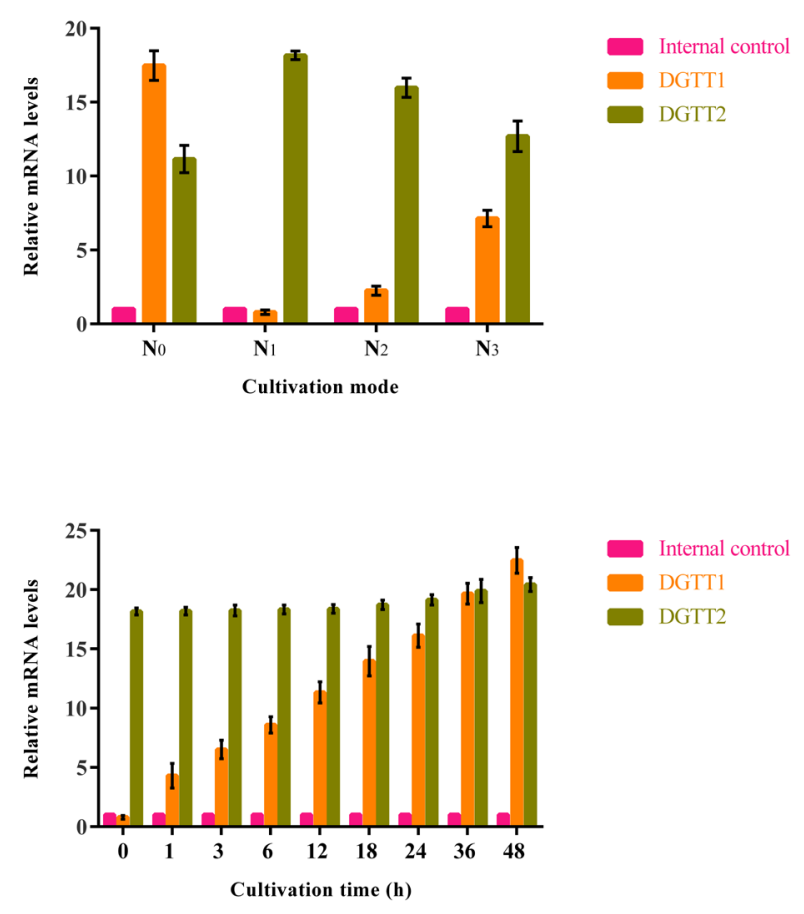

Figure 3: DGTT1 and DGTT2 gene expression in a) different times, b) different concentrations.

strategy could be considered as a powerful parameter to maximize the lipid production yields. Besides, C. reinhardtii prefers to accumulate biomass in nitrogen rich medium instead of increasing its lipid contents. The same trends have been observed in other C. reinhardtii strains. ${ }^{16}$

\section{qRT-PCR analysis of DGTT1 and DGTT2 genes}

To investigate the effects of nitrogen starvation on the expression levels of two major genes involved in TAG accumulation in C. reinhardtii microalga, qRT-PCR analysis was performed. To accomplish a successful real time PCR analysis, the employed primers are considered as a critical point. Due to its great sensitivity and robust performance, we chose AlleleID 7.5 software to design the requested primers. A previously sequenced ribosomal gene ( $18 \mathrm{~S}$ rRNA) from another $C$. reinhardtii strain was selected as the internal control gene to normalize the observed data. Figure 3a displays the obtained results from quantitative analysis of DGTT1 and DGTT2 expression profiles during normal and nitrogen starved conditions. The expression levels for DGTT1 transcript showed a significant increase $\left(21.05,7.76\right.$ and 2.45-fold increase than $\mathrm{N}_{1}, \mathrm{~N}_{2}$ and $\mathrm{N}_{3}$, respectively) in nitrogen depleted medium $\left(\mathrm{N}_{0}\right)$ in comparison with its values in nitrogen containing media. On the other hand, the DGTT2 transcript in $\mathrm{N}_{0}$ exhibited $0.61,0.70$ and 0.88 -fold decrease compared with $\mathrm{N}_{1}, \mathrm{~N}_{2}$ and $\mathrm{N}_{3}$, culture media respectively.

The statistical analysis (Kruskal-Wallis analysis with Tukey's post hoc analysis) proved the significant influence of nitrogen starvation on the relative expression of DGTT1 ( $p$-value: 0.0189 ) and DGTT2 ( $p$-value: 0.0168). Culture medium without nitrogen $\left(0 \mathrm{~g} \mathrm{NaNO}_{3}\right)$ showed the highest DGTT1 expression. Besides, a gradual increase was observed in DGTT1 expression pattern from nitrogen starved to culture media with higher nitrogen concentration.

In nitrogen starvation condition, DGTT1 upregulation was happened within the first three hour and was kept in its elevated amounts during cultivation up to $36 \mathrm{~h}$ in comparison with the normal cultivation condi- 
tions with a normal decrease during $48 \mathrm{~h}$ of study Figure $3 \mathrm{~b}$. There was not a significant difference $(p \leq 0.05)$ for DGTT2.

Until now, some researchers have been dealt with the effects of nitrogen starvation on the physiology and metabolic pathways in C. reinhardtii. ${ }^{20}$ The results of previous studies have shown that the relative expression profiles of DGTT1 and DGTT2 genes differs under nitrogen, iron, sulfur and phosphorous. ${ }^{21,22}$

Using qRT-PCR analysis, we showed that nitrogen starvation of a naturally isolated C. reinhardtii strain results to high expression levels of DGTT1 over observed levels from other nitrogen containing media. Remarkably, though the total produced lipid content was higher in nitrogen starved strain, but the total obtained biomass (dry cell weight) was lesser than nitrogen rich conditions. This phenomenon indicates that nitrogen deprivation might divert the cellular resources towards lipid production instead of biomass biosynthesis. Recently, omics-based approaches ${ }^{23}$ and metabolic flux analysis data ${ }^{24}$ has been stablished for C. reinhardtii. The results of the current study could be helpful in researches concerning systems biology and biotechnology of this microalga.

\section{Triacylglycerol content of lipids}

In optimized physiologic conditions, $C$. reinhardtii tends to synthetize fatty acids mainly for esterification towards glycerol-based membrane lipids. ${ }^{5}$ On the other hand, during deprivation conditions, the lipid biosynthetic pathway alters towards neutral lipid accumulation such as TAGs. TAGs, are considered as storage molecules which will quickly degraded in optimal conditions to produce the demanded cellular energy. ${ }^{25}$ Among the five major enzymes involved in TAG biosynthesis, DGTT1 and DGTT3 are known to be only active in nutrient rich media. On the other hand, DGTT2, DGTT4 and DGTT5 have not a distinct contribution in TAG biosynthesis during normal conditions. During different nutrient starvation, such as zinc, iron, phosphorus, sulfur and nitrogen, DGTT1 and DGAT1 levels exhibit a significant increase. Besides, it has been shown that DGTT2 displays a great role in TAG accumulation during nitrogen or phosphorus starvation. ${ }^{26}$

The total content of TAGs from the obtained lipids were quantified and compared in for different cultivation modes Figure 4 . The obtained data show an increasing trend towards TAG accumulation in lower nitrogen levels. In nitrogen rich, medium $\left(\mathrm{N}_{1}\right)$ only $0.186 \mathrm{~g} \mathrm{~L}^{-1}$ of the total produced lipids were TAG (14\%). In nitrogen, limited media $\left(\mathrm{N}_{2}\right)$ and $\left(\mathrm{N}_{3}\right)$ the maximum amounts of $0.175 \mathrm{~g} \mathrm{~L}^{-1}$ and $0.164 \mathrm{~g} \mathrm{~L}^{-1} \mathrm{TAGs}$ was observed which were equal to $21 \%$ and $26 \%$ of the total obtained lipids, respectively.

Microalgae are a good choice for fatty acids accumulation. ${ }^{27}$ Noticeably, the highest amount of TAG accumulation ( $\left.0.299 \mathrm{~g} \mathrm{~L}^{-1}, 0.38 \%\right)$ was reported in nitrogen starved medium $\left(\mathrm{N}_{0}\right)$.

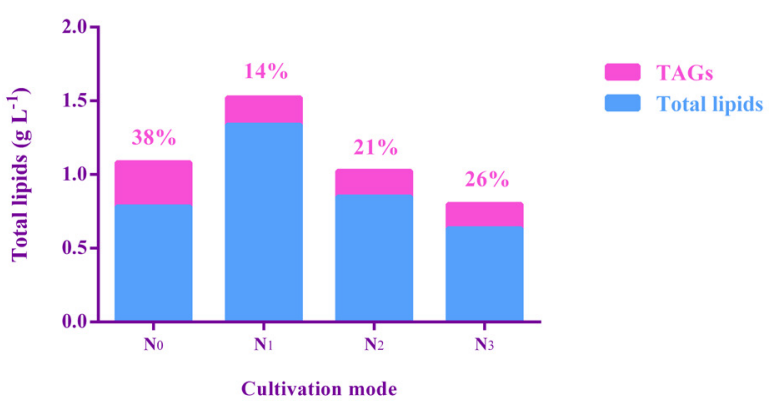

Figure 4: Total triacylglycerol (TAG) concentration (the upper segment of each column) obtained from four different nitrogen levels compared with the total produced lipid (the whole column). The presented results are the calculated mean values from triplicate experiments.
In despite of several advantages over other competitive resources such as microbes or plants, biodiesel production from microalgae have some shortcomings such as lower lipid production and productivities. ${ }^{28}$ In this study, we showed the applicability of using nutrient stress strategy to redirect the microalgal metabolic pathways towards non-polar lipids and mainly TAGs. Real-time reverse-transcription PCR (qRT-PCR) analysis of this strain confirmed high expression level of DGTT1 over the level observed in the control strain.

The precise mechanisms involved in the overexpression of metabolic pathways for TAG biosynthesis are not clearly determined. The results of the current study could shed light on the exact metabolic and biochemical changes due to nitrogen deficiency. Besides, the results of this study could suggest potential metabolic networks for genetic or metabolic engineering and for better understanding of the C. reinhardtii systems biotechnology for biomass and lipid production.

Notably, in this study a maximum level of $42.07 \%$ for lipid accumulation was shown in a robust $C$. reinhardtii strain which warrants further optimization and scale-up studies for large scale lipid and biomass production.

\section{CONCLUSION}

The obtained results, deciphered the metabolic and biochemical response of a naturally isolated strain of $C$. reinhardtii to nitrogen limitation conditions. Besides the quantitative changes in DGTT1 and DGGT2 expression profiles was determined and elucidated new targets for metabolic engineering of $C$. reinhardtii for TAG overexpression and other valuable bioactive compounds. Furthermore, the results demonstrated the ability of $C$. reinhardtii to produce TAGs for green energy production and other purposes.

\section{ACKNOWLEDGEMENT}

We would like to kindly acknowledge Dr. Taylor L. Weiss and Prof. Ursula Goodenough (Department of Biology, Washington University, Saint Louis, MO 63130, US) for sharing their original TAG assay protocol used in this work.

\section{CONFLICT OF INTEREST}

The authors declare no conflict of interest.

\section{ABBREVIATIONS USED}

DGAT: Diacylglycerol transferase; PDAT: Phospholipid: diacylglycerol acyltransferase; qRT-PCR: Quantitative real-time polymerase chain reaction; TAG: Triacylglycerol.

\section{REFERENCES}

1. Li Y, Horsman M, Wu N, Lan CQ, Dubois-Calero N. Biofuels from microalgae. Biotechnol Prog. 2008;24(4):815-20

2. Rodolfi L, Zittelli GC, Bassi N, Padovani G, Biondi N, Bonini G, et al. Microalgae for oil: Strain selection, induction of lipid synthesis and outdoor mass cultivation in a low-cost photobioreactor. Biotechnol Bioeng. 2009;102(1):10012.

3. Chen $C Y$, Yeh KL, Aisyah R, Lee DJ, Chang JS. Cultivation, photobioreactor design and harvesting of microalgae for biodiesel production: A critical review. Bioresour Technol. 2011;102(1):71-81.

4. Courchesne NMD, Parisien A, Wang B, Lan CQ. Enhancement of lipid production using biochemical, genetic and transcription factor engineering approaches. J Biotechnol. 2009;141(1):31-41.

5. Hu Q, Sommerfeld M, Jarvis E, Ghirardi M, Posewitz M, Seibert $M$, et al. Microalgal triacylglycerols as feedstocks for biofuel production: Perspectives and advances. Plant J. 2008;54(4):621-39.

6. Scranton MA, Ostrand JT, Fields FJ, Mayfield SP. Chlamydomonas as a model for biofuels and bio-products production. Plant J. 2015;82(3):523-31.

7. Merchant SS, Prochnik SE, Vallon O, Harris EH, Karpowicz SJ, Witman GB, et al. The Chlamydomonas genome reveals the evolution of key animal and plant 
functions. Science. 2007;318(5848):245-50.

8. Chen JE, Smith AG. A look at diacylglycerol acyltransferases (DGATs) in algae. J Biotechnol. 2012;162(1):28-39.

9. Hung $\mathrm{CH}$, Ho MY, Kanehara K, Nakamura Y. Functional study of diacylglycerol acyltransferase type 2 family in Chlamydomonas reinhardtii. FEBS Lett. 2013;587(15):2364-70.

10. Blaby IK, Glaesener AG, Mettler T, Fitz-Gibbon ST, Gallaher SD, Liu B, et al. Systems-level analysis of nitrogen starvation-induced modifications of carbon metabolism in a Chlamydomonas reinhardtii starchless mutant. Plant Cell. 2013:25(11):4305-23

11. Boyle NR, Page MD, Liu B, Blaby IK, Casero D, Kropat J, et al. Three acyltransferases and nitrogen-responsive regulator are implicated in nitrogen starvation-induced triacylglycerol accumulation in Chlamydomonas. J Biol Chem. 2012;287(19):15811-25

12. Rippka R, Deruelles J, Waterbury JB. Generic assignments, strain histories and properties of pure cultures of cyanobacteria. J Gen Microbiol. 1979;111(1):1-61.

13. Morowvat MH, Rasoul-Amini S, GhasemiY. Chlamydomonas as a "new" organism for biodiesel production. Bioresour Technol. 2010;101(6):2059-62.

14. Livak KJ, Schmittgen TD. Analysis of relative gene expression data using realtime quantitative PCR and the $2^{-\triangle \Delta C T}$ method. Methods. 2001;25(4):402-8.

15. Morowvat $\mathrm{MH}$, Ghasemi Y. Culture medium optimization for enhanced $\beta$-carotene and biomass production by Dunaliella salina in mixotrophic culture. Biocatal Agric Biotechnol. 2016;7:217-23.

16. Cakmak T, Angun P, Demiray YE, Ozkan AD, Elibol Z, Tekinay T. Differential effects of nitrogen and sulfur deprivation on growth and biodiesel feedstock production of Chlamydomonas reinhardtii. Biotechnol Bioeng. 2012;109(8):1947-57.

17. Kamalanathan $M$, Pierangelini $M$, Shearman LA, Gleadow R, Beardall J. Impacts of nitrogen and phosphorus starvation on the physiology of Chlamydomonas reinhardtii. J Appl Phycol. 2016;28(3):1509-20.

18. Nakanishi A, Aikawa S, Ho SH, Chen CY, Chang JS, Hasunuma T, et al. Develop- ment of lipid productivities under different $\mathrm{CO}_{2}$ conditions of marine microalgae Chlamydomonas sp. JSC4. Bioresour Technol. 2014;152:247-52.

19. Tevatia R, Demirel Y, Blum P. Kinetic modeling of photoautotropic growth and neutral lipid accumulation in terms of ammonium concentration in Chlamydomonas reinhardtii. Bioresour Technol. 2012;119:419-24.

20. Miller R, Wu G, Deshpande RR, Vieler A, Gartner K, Li X, et al. Changes in transcript abundance in Chlamydomonas reinhardtii following nitrogen deprivation predict diversion of metabolism. Plant physiol. 2010;154(4):1737-52.

21. Hernández-Torres A, Zapata-Morales AL, Alfaro AE, Soria-Guerra RE. Identification of gene transcripts involved in lipid biosynthesis in Chlamydomonas reinhardti under nitrogen, iron and sulfur deprivation. World J Microbiol Biotechnol. 2016;32(4):55.

22. Iwai M, Ikeda K, Shimojima M, Ohta H. Enhancement of extraplastidic oil synthesis in Chlamydomonas reinhardtii using a type-2 diacylglycerol acyltransferase with a phosphorus starvation-inducible promoter. Plant Biotechnol J. 2014;12(6):808-19.

23. Schmollinger S, Mühlhaus T, Boyle NR, Blaby IK, Casero D, Mettler T, et al. Nitrogen-sparing mechanisms in Chlamydomonas affect the transcriptome, the proteome, and photosynthetic metabolism. Plant Cell. 2014;26(4):1410-35.

24. Boyle NR, Morgan JA. Flux balance analysis of primary metabolism in Chlamydomonas reinhardtii. BioMed Central Systems Biol. 2009;3(1):4-4.

25. Merchant SS, Kropat J, Liu B, Shaw J, Warakanont J. TAG, You're it! Chlamydomonas as a reference organism for understanding algal triacylglycerol accumulation. Curr Opin Biotechnol. 2012;23(3):352-63.

26. Goodenough U, Blaby I, Casero D, Gallaher SD, Goodson C, Johnson S, et al. The path to triacylglyceride obesity in the sta6 strain of Chlamydomonas reinhardtii. Eukaryot Cell. 2014;13:591-613.

27. Ghasemi Y, Rasoul-Amini S, Morowvat MH. Algae for the production of SCP, in Bioprocess Sciences and Technology. Nova Science Publishers, Inc. 2011:163-84.

28. Chisti Y. Biodiesel from microalgae. Biotechnol Adv. 2007;25(3):294-306.

Article History: Submission Date : 29-05-2017 ; Revised Date : 07-06-2017; Acceptance Date : 31-07-2017.

Cite this article: Morowvat MH, Ghasemi Y. Impacts of Nitrogen Starvation on Expression Profiles of Involving Genes in Triacylglycerol Biosynthesis in Chlamydomonas reinhardtii: Towards Microalgal Systems Biotechnology. J Young Pharm. 2017;9(4):496-501. 